Original Research Paper

\title{
Contamination Risk Evaluation of Groundwater in the Canton of Portoviejo-Ecuador, using Susceptibility Index and two Intrinsic Vulnerability Models
}

\author{
${ }^{1,2}$ Suhail Sharadqah \\ ${ }^{I}$ Department of Natural Resources and Chemical Engineering, Tafila Technical University, Tafila, Jordan \\ ${ }^{2}$ Faculty of Agricultural Engineering, Manabi Technical University, Portoviejo, Ecuador
}

\author{
Article history \\ Received: 25-10-2016 \\ Revised: $17-01-2017$ \\ Accepted: 06-02-2017 \\ Postal address: P.O. Box (179) \\ Tafila 66110, Jordan \\ Tel: +962797150660 \\ Email: suhail_sharadaqah@yahoo.es
}

\begin{abstract}
The present study aims to investigate the applicability of DRASTIC, GOD and SI models in evaluating the groundwater vulnerability and risk of contamination in the Canton of Portoviejo, Ecuador. The groundwater vulnerability to contamination has been evaluated using DRASTIC and GOD models. Both models were able to classify the study area into different sectors of variable vulnerability. The coincidence of the two models is high, especially in the sectors with high vulnerability. Evaluation of the groundwater risk of contamination has been carried out by combining the contaminant load index with the elaborated groundwater vulnerability classes using DRASTIC and GOD methodologies. The resultant maps of both models reveal that in the areas with high vulnerability the land usages tend to introduce high contaminant load and therefore, the groundwater beneath these areas is subject to higher risk of contamination. The risk maps elaborated using DRASTIC and GOD models have more coincidence than vulnerability maps elaborated using the same models. This is partially because of the contaminant load index which is identical in the both cases. The groundwater risk of contamination has been also evaluated using Susceptibility Index (SI) model. The resultant SI risk map was compared with the risk maps elaborated using DRASTIC and GOD. The results indicate a comparable products; however, they have more similarity with DRASTIC outputs. The maps of groundwater risk of contamination in the canton using different models show a comparable results, especially when accepting one risk category shift as acceptable error. The coincidence in this case is 98,94 and $88 \%$ between DRASTIC and GOD, DRASTIC and SI, GOD and SI respectively. The results of the study recommend SI and GOD models to study the risk of groundwater contamination especially in data limitation conditions.
\end{abstract}

Keywords: Manabi Province, DRASTIC Model, GOD Model, Portoviejo River, Groundwater Protection, Groundwater Contamination, Vulnerability

\section{Introduction}

In spite of thousands of articles dealt with the term vulnerability, there is no agreement on the exact definition (Albuquerque et al., 2013; Stigter et al., 2006). The classic definition of aquifer vulnerability according to Vrba and Zoporozec (1994) is "an intrinsic property of a groundwater system that depends on the sensitivity of that system to human and/or natural impacts". While Albinet and Margat (1970) state that groundwater vulnerability is "the possibility of percolation and diffusion of contaminants from the ground surface into natural water-table reservoirs under natural conditions". Additionally, Olmar and Rezac (1974) define the term vulnerability as "the danger of endangerment, determined by natural conditions and independent of present source of pollution". 
Vrba and Zaporozec (1994) distinguished between the intrinsic and the specific vulnerability. The intrinsic (natural) vulnerability was purely defined as a function of hydrogeological factors and the specific vulnerability that is related to specific pollutants. On world wide scale, the majority of vulnerability studies deal with the intrinsic vulnerability and take into account only the natural parameters (Sasal et al., 2011; Voudouris et al., 2010; Jaunat et al., 2016; Gougazeh and Sharadqah, 2009; Sharadqah, 2001; 2011; 2015a).

As vulnerability concept, the term of groundwater risk of contamination is still ambiguous for many researchers. In some studies the intrinsic vulnerability dealt and referred to by risk term and vice versa (Albuquerque et al., 2013; Al-Rawabdeh et al., 2014; Gaieb and Hamza, 2013).

Risk linguistically means the chance or situation involving such a possibility (Oxford English Dictionary). Depending on this definition, the risk of groundwater contamination may be understood as the chance or probability of such contamination to occur. The probability of contamination is governed by vulnerability and the presence of contaminant. Therefore, evaluating the groundwater vulnerability to contamination is prerequisite for evaluation the risk of contamination of groundwater. This is totally coincided with the definition of Foster and Hirata (1988), in which they define the groundwater pollution risk as "the interaction between the natural vulnerability of an aquifer and the pollution loading that is or will be applied on the surface environment as a result of human activity". Sharadqah (2004) adopted the same definition and suggested an index for contaminant load depending on land use. This index has been used in several studies and it demonstrates clarity, easiness to handle and applicability (Sharadqah, 2010; 2015b).

Protection of groundwater quality is an action and a responsibility that can be practiced efficiently through knowledge of the degree of groundwater susceptibility. Vulnerability maps are a visualization for groundwater susceptibility. Without a good evaluation of groundwater vulnerability to contamination, protection measures may be insufficient and therefore these waters may be contaminated, or these measures may be exaggerated that might lead to an improper land use.

Thus, the study of groundwater vulnerability to pollution can be considered as the first stage in the process of groundwater quality protection, or the scientific participation in the process of protection which is the responsibility of the authority and stakeholders as established by the Ecuadorian Water Law approved by the National Assembly on June 24, 2014.

The deterioration of the quality of groundwater and surface water in the Canton of Portoviejo is a well known problem (Macias and Dيaz, 2010; Garcia et al., 2010). The pollution sources are numerous and represent various sectors in which the most prominent are domestic, agricultural and industrial sectors. The wide range of contaminants originated from those sectors turned the quality of Portoviejo river from usable to harmful (Macias and Dيa, 2010). The nitrogen load to the river from wastewater source only is estimated at $1360000 \mathrm{~kg} /$ year (Macias and Dيaz, 2010). Groundwater is not fully isolated from the surface water and the river itself being contaminated may represent a major threat to the quality of groundwater. Furthermore, contaminants that are already available can reach groundwater washed by water infiltrated through the soil and vadose zone. However, the concentration of nitrate in the waters of the river has not exceeded the limit of 50 $\mathrm{mg} \mathrm{L}^{-1}$ (Reina and Zambrano, 2012; Garcia et al., 2010).

Nitrate is a contamination indicator of groundwater due to its highly solubility, where it practically moves with the water that drags it (Nolan et al., 2002; Stumm and Morgan, 1996). This contaminant could move from the groundwater into the river when the groundwater level reaches the river. Groundwater can be recharged by the river water and in this case, contaminants such as nitrate can reach underground water. The waters of the Portoviejo River can contaminate groundwater with nitrate, but if there is no other source of contamination, the concentrations will not exceed the allowed limit since the $\mathrm{NO}_{3}$ concentration in the river waters is less than $50 \mathrm{ppm}$ (Reina and Zambrano, 2012). Actually, this is not the case, since there are many uses in the Canton area that could contaminate the groundwater with nitrate, particularly the agricultural sector which uses large amounts of nitrogen and organic fertilizers (Garcia et al., 2010).

Therefore, assessing and mapping groundwater vulnerability to contamination help the stakeholders and decision makers to locate where groundwater can be easily contaminated and where not. This in turn helps to decide which activities can be allowed in certain areas in order to maintain or even improve the quality of groundwater in accordance with good land-use practices (Kumar et al., 2015; Aller et al., 1987).

The three models used in this study are widely applied in extensive studies worldwide. DRASTIC model is one of the most widely used for groundwater vulnerability evaluation. It has been applied in many countries on all continents. For example in USA (Rupert, 2001; Beynen et al., 2012), Jordan (Gougazeh and Sharadqah, 2009), Portugal (Stigter et al., 2006; Lobo-Ferreira and Oliveira, 2003), Cyprus 
(Voudouris et al., 2010), Ecuador (Sharadqah, 2015a), Argentina (Sasal et al., 2011), Sweden (Rosen, 1994), South Africa (Lynch et al., 1997), Japan (Babiker et al., 2005), among many others. The Susceptibility Index (SI) method (Ribeiro, 2000), is an adaptation of the DRASTIC methodology. It was applied in several countries such as Algeria (Abdelmajid and Omar, 2009), Portugal ((Ribeiro et al., 2003; Lobo-Ferreira and Oliveira, 2003; Stigter et al., 2006), Tuniz (Gaieb and Hamza, 2013), India (Brindha and Elango, 2015). GOD model has the least requirement of data among the three modes. Since its development it was applied to numerous case studies in Canada (Golder and Monahan, 2005), China (Xu et al., 2013), Brazil (Barboza et al., 2007; Vogel, 2008; Tavares et al., 2009)), Iran (Ghazavi and Ebrahimi, 2015), Nicaragua (Mendoza and Barmen, 2006).

The present study aims to investigate the applicability of DRASTIC, GOD and SI models in evaluating the groundwater vulnerability and risk of contamination in the study area.

\section{Study Area}

Portoviejo Canton forms the capital of the Manabí Province which is located in the Pacific coastal region of Ecuador (Fig. 1). The most important feature in the Canton is Portoviejo River, which influences the demographic distribution and the land uses. In the flat areas that surrounding the river the majority of the Canton population reside and the horticulture is the dominant land use (Fig. $2 \mathrm{a}$ and $2 \mathrm{~b}$ ). The canton climate belongs to the pacific costal regimen and the long term annual precipitation ranges from more than $1000 \mathrm{~mm} / \mathrm{y}$ to less than $300 \mathrm{~mm} / \mathrm{y}$ (INAMHI, 2106). Hydrogeologically, the quaternary deposits close to river course, such as Onszole and San Mateo Formations could form an aquifers. The majority of other formations are dominantly clay, shale or lutites; however, they become locally or in some horizons more sandy. Therefore, the possibility of storing some water cannot be rule out.

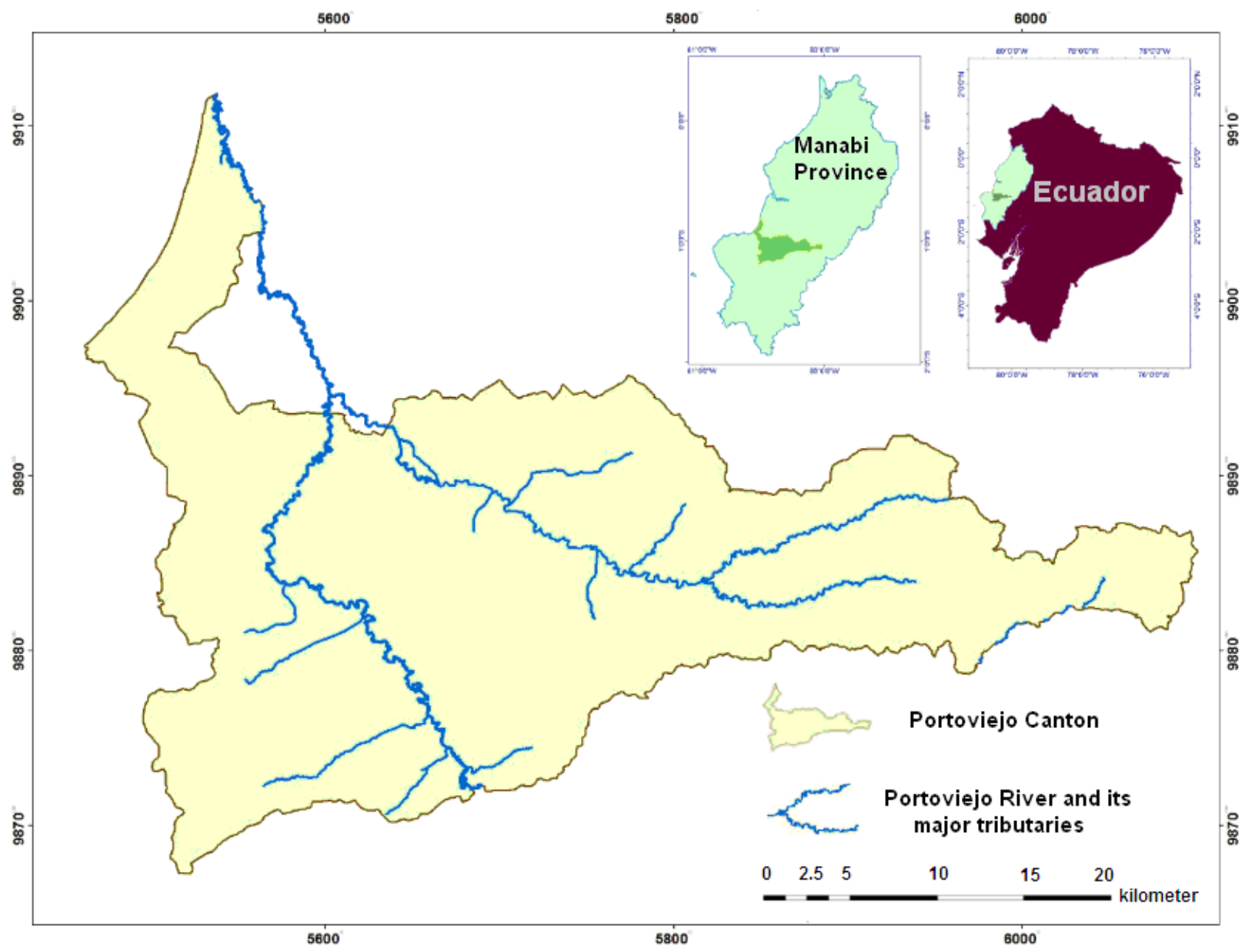

Fig. 1. Study area map 

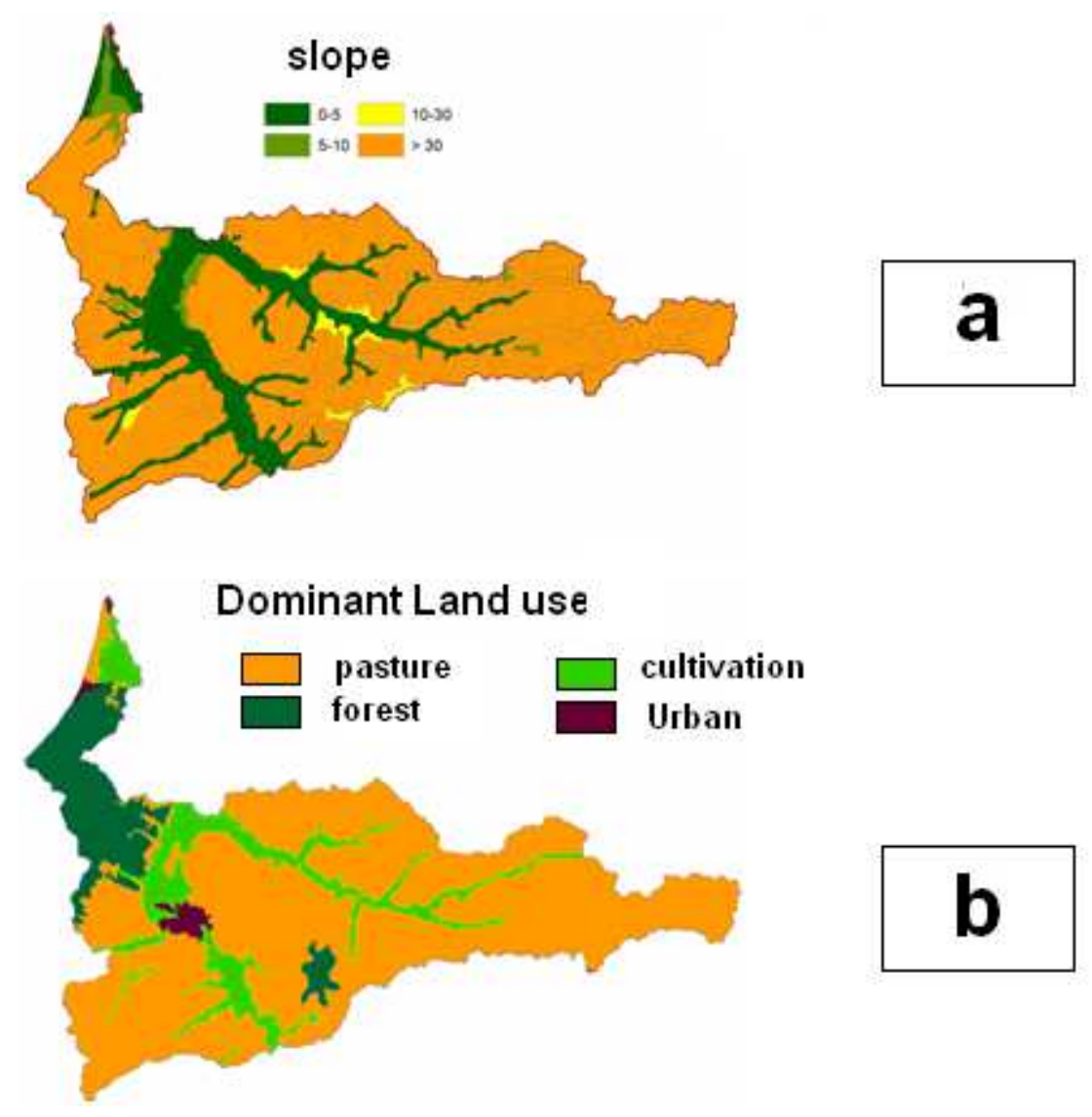

Fig. 2. (a) Topographical slope of study area (\%) (b) Dominant land use in study area

\section{Methodology}

\section{Groundwater Vulnerability to Contamination Study}

To assess groundwater vulnerability to contamination which is sometimes a prerequisite to evaluate the risk of groundwater contamination, two intrinsic methodologies have been adopted. These are DRASTIC methodology (Aller et al., 1987) and GOD Methodology (Foster, 1987). The three models used in the actual study are belong to Overlay and Index Methods (OIM). This type of methods is based on combining maps of various physiographic attributes by assigning a score to each attribute (NRC, 1993). Qualitative or sometimes quantitative indices are derived, that bring together the key factors that govern the contaminant transport from the land surface to groundwater (e.g., depth to groundwater, net recharge, geology) (Connell and van den Daele, 2003). Thus OIM-based ground water vulnerability mapping models essentially integrate ratings and attributes of those important factors (Hamerlinck and Ameson, 1998). In the simplest methodologies, maps of attributes are overlaid and areas with a combination of certain characteristics (e.g., shallow groundwater table with high net recharge) are evaluated as having higher vulnerability.

\section{DRASTIC Vulnerability}

DRASTIC Vulnerability maps of the study area have been elaborated depending on the hydrogeological framework parameters and based on seven mapped parameters (Table 1). Each parameter has been separately evaluated and then superimposed all to get the DRASTIC index (Equation 1). This index is then reclassified using GIS software to different vulnerability classes producing DRASTIC map of groundwater vulnerability to contamination:

$D I=5 D r+4 R r+3 A r+2 S r+T+5 I r+3 C r$

Where:

DI $\quad=$ DRASTIC Index

$5,4, \ldots 3=$ Parameters weights

$r \quad=$ Rating

$D, R, A, S, T, I, C=$ DRASTIC model parameters

DRASTIC parameters, weights and ratings are defined in Table 1. 
Table 1. Drastic model weights and ratings (modified after Aller et al., 1987)

\begin{tabular}{lllll}
\hline DRASTIC parameters & Parameter symbol & Weight & Range & Rating \\
\hline Depth to Water (m) & $\mathrm{D}$ & 5 & 30.3 to $0>$ & 1 to 10 \\
Net Recharge (mm) & $\mathrm{R}$ & 4 & 0 to $>254$ & 1 to 9 \\
Aquifer media & $\mathrm{A}$ & 3 & Massive Shale to Limestone karst & 1 to 10 \\
Soil media & $\mathrm{S}$ & 2 & No shrinking clay to absent & 1 to 10 \\
Topography (\%) & $\mathrm{T}$ & 1 & 18 to $0>$ Confining layer to limestone karst & 1 to 10 \\
Impact of vadose zone & $\mathrm{I}$ & 5 & & 1 to 10 \\
hydraulic Conductivity (m/day) & $\mathrm{C}$ & 3 & 0.4 to $>82$ & 1 to 10 \\
\hline
\end{tabular}

Table 2. GOD model Ratings (modified after Foster, 1987)

\begin{tabular}{lll}
\hline Parameter & Range & Rating \\
\hline $\mathrm{G}$ & No aquifer to unconfined aquifer & 0 to 1 \\
$\mathrm{O}$ & Clay to karstified limestone & 0.4 to 1 \\
$\mathrm{D}$ & 100 to $0(\mathrm{~m})$ & 0.4 to 1 \\
\hline
\end{tabular}

Table 3. SI model: Weights, ranges and rating

\begin{tabular}{lllll}
\hline SI parameters & Parameter symbol & Weight & Range & Rating \\
\hline Depth to Water $(\mathrm{m})$ & $\mathrm{D}$ & 0.186 & 30 to $0>$ & 01 to 100 \\
net Recharge $(\mathrm{mm})$ & $\mathrm{R}$ & 0.212 & 0 to $>254$ & 0 to 100 \\
Aquifer media & $\mathrm{A}$ & 0.259 & Massive Shale to Limestone karst & 0 to 100 \\
Topography $(\%)$ & $\mathrm{T}$ & 0.121 & 18 to $0>$ & 0 to 100 \\
Land use & LU & 0.222 & Water bodies to Industrial & 0 to 100 \\
\end{tabular}

\section{GOD Vulnerability}

GOD model is one of the easiest methods to evaluate the vulnerability of groundwater to contamination. It includes only three parameters. Those are Groundwater occurrence (G), Overall aquifer class (O) and Depth to groundwater (D) (Foster, 1987). GOD vulnerability index is obtained by applying the multiplicative formula of GOD model (equation 2). This index is then reclassified to different GOD vulnerability classes:

$G O D$ index $=G r * O r * D r$

Where:

$r \quad=$ The parameter rating that can be shown in
Table 2 $G, O, D=$ The $G O D$ model Parameters

\section{Groundwater Contamination Risk Mapping}

To evaluate the groundwater risk of contamination in the study area, three models have been applied: DRASTIC model combined with the contaminant load, GOD model combined with contaminant load and SI model. The contaminant load map derived from the land use map (Fig 2b). Each use assigned a unique contaminant load. The forest area assigned low contaminant load, the pastures and arable assigned moderate contaminant load and the cultivated area which subjected to natural and chemical fertilizers assigned high contaminant load. The Risk categories then obtained as the matrix solution (Fig. 3).

The Susceptibility Index "SI" model is a modification of DRASTIC method (Ribeiro, 2000). SI method applies four of DRASTIC seven parameter with their corresponding nomenclatures and add a fifth parameter which is Land Use (LU). Each of the five parameters has a weight and assigned a rating value ranges between 0 and 100 (Table 3). The overall SI risk index is calculated as shown in the Equation 3 and then reclassified for different risk classes (Table 4):

$$
\begin{aligned}
& S I=0.186 \mathrm{Dr}+0.212 R r \\
& +0.259 \mathrm{Ar}+0.121 \mathrm{Tr}+0.222 L U r
\end{aligned}
$$

Where:

$$
\begin{array}{ll}
\text { SI } & =\text { Susceptibility Index } \\
0.186,0.212 . ., 0.222 & =\text { Parameters weights } \\
r & =\text { Rating } \\
D, R, A, T, L U & =\text { SI Parameters }
\end{array}
$$

Mapping the vulnerability and risk of groundwater contamination required data processing, classification, evaluation. All the data management processing for all factors considers by the three models have been concluded in an integrated GIS environment. Initiating from the row source data (Table 5), an exhaustive data manipulation and data management processes have been done to come out with parameters ratings layers. 
Suhail Sharadqah / American Journal of Environmental Sciences 2017, 13 (1): 65.76

DOI: $10.3844 /$ ajessp.2017.65.76

Table 4. Criteria for the Risk evaluation using SI method

\begin{tabular}{llllll}
\hline Risk Category & Very Low & Low & Moderate & High & Very High \\
\hline SI Index & $<40$ & $40-50$ & $50-70$ & $70-80$ & $>80$ \\
\hline
\end{tabular}

Modified after (Ribeiro, 2000)

Table 5. Data used to generate the parameters ratings, their format, source and extension

\begin{tabular}{|c|c|c|c|c|c|c|}
\hline \multirow[b]{2}{*}{ Information Layer } & \multirow[b]{2}{*}{ Format } & \multirow[b]{2}{*}{ Source } & \multirow[b]{2}{*}{ Extension } & \multicolumn{3}{|c|}{ Generated parameter } \\
\hline & & & & DRASTIC & GOD & SI \\
\hline wells & Excel sheet & SENAGA, Portoviejo * & Portoviejo Canton & $\mathrm{D}$ & $\mathrm{D}$ & $\mathrm{D}$ \\
\hline Recharge & paper map & $\mathrm{CRM} * *$ & Manabí Province & $\mathrm{R}$ & - & $\mathrm{R}$ \\
\hline Hydrogeology & Digital map & MAGAP (2005a) & National & $\mathrm{A}, \mathrm{C}, \mathrm{I}$ & $\mathrm{G}, \mathrm{O}$ & A \\
\hline Geological & Digital map & MAGAP (2005b) & National & $\mathrm{A}, \mathrm{C}, \mathrm{I}$ & $\mathrm{G}, \mathrm{O}$ & A \\
\hline Taxonomy & Digital map & MAGAP (2002a) & Manabí Province & $\mathrm{S}$ & - & - \\
\hline DEM & Digital & $\begin{array}{l}\text { Provincial Council } \\
\text { of Manabí }\end{array}$ & Manabí Province & $\mathrm{T}$ & - & $\mathrm{T}$ \\
\hline Land use map & Digital map & MAGAP (2002c) & Manabí Province & $\begin{array}{l}\text { Contaminant } \\
\text { load }\end{array}$ & $\begin{array}{l}\text { Contaminant } \\
\text { load }\end{array}$ & LU \\
\hline Map of soil texture & Digital map & MAGAP (2002b) & Manabí Province & S & - & - \\
\hline Weather data & $\begin{array}{l}\text { Text and spread } \\
\text { sheets }\end{array}$ & INAMHI (2014) & Manabí Province & $\mathrm{R}$ & - & $\mathrm{R}$ \\
\hline
\end{tabular}

SENAGA: National Secretary for Water. (Not Published data)

CRM (Manabí Rehabilitation Center): Predecessor Entity to SENAGA. (Not Published data)

\section{Contaminant Load}
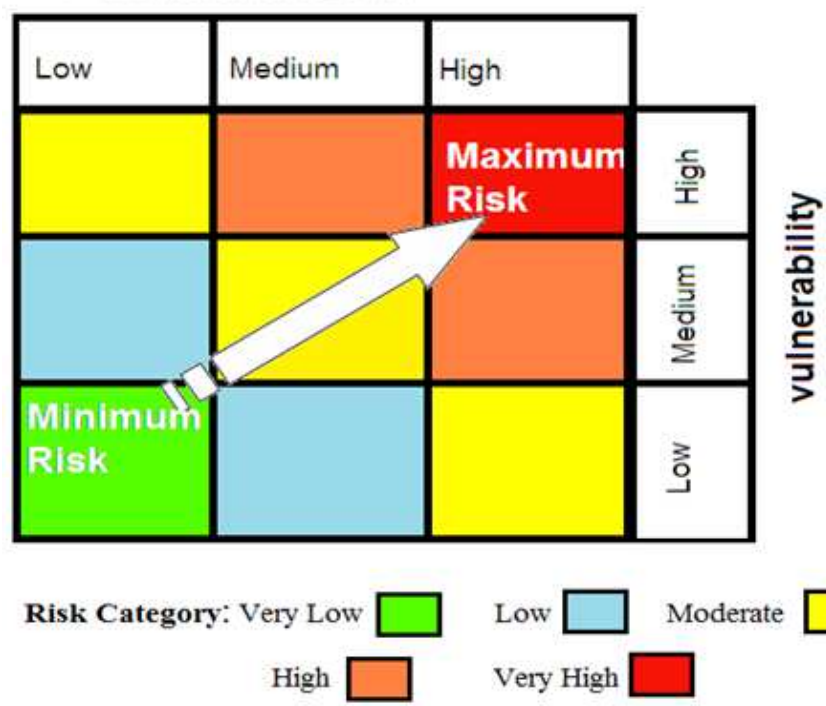

Fig. 3. Risk matrix obtained by combining vulnerability class with contaminant load (modified after Sharadqah, 2004)

\section{Results and Discussion}

The results show that DRASTIC and GOD models are able to classify the groundwater's vulnerability of the study area to distinct levels (Fig. 4).

The two models agree that the flat area around the Portoviejo River is more vulnerable than the tilted areas away from the river. In this flat area, the groundwater is very shallow and the aquifer is of the quaternary deposits. This shows that the combination of the D, A and $\mathrm{T}$ parameters of the DRASTIC model have the greatest contribution in the distribution of the DRASTIC vulnerability classes. Likewise, the D and O parameters of the GOD model have the greatest contribution in the distribution of the GOD vulnerability classes. The results of vulnerability distribution as percentage of study area using GOD and DRASTIC models are shown in Fig. 5. However; the two model don't totally coincide in the spatial distribution of each vulnerability class. Consequently, These result might be misleading if the spatial relationships ignored. Because it might find a similar 
areal percentage of certain vulnerability class derive from two different model, but the spatial distribution of these areas could be different. Table 6 lists the spatial coincidence of the groundwater vulnerability classes derived by the two models. The results show that the spatial coincidence between DRASTIC and GOD vulnerability classes is $43 \%$. But the majority of differences between the two models is within one degree of difference. So, if one class shift is accepted as acceptable error, the coincidence between the two models reach $76 \%$ which is similar or even more than what reported in some studies (Abdelmajid and Omar,
2009; Gogu et al., 2003). As in many studies, GOD model ascribe more areas a high vulnerability (Gogu et al., 2003; Díaz et al., 2009).

The results of the risk study show closer results obtained from the three models (Fig. 6). That's essentially due to unified contaminant load distribution in the three models. So the variability in the groundwater risk to contamination will depend only on the vulnerability. As vulnerability influence is only $50 \%$ on risk classes in case of DRASTIC and GOD and $78 \%$ in case of SI method, consequently the outputs of models for risk study will have less variation than vulnerability.

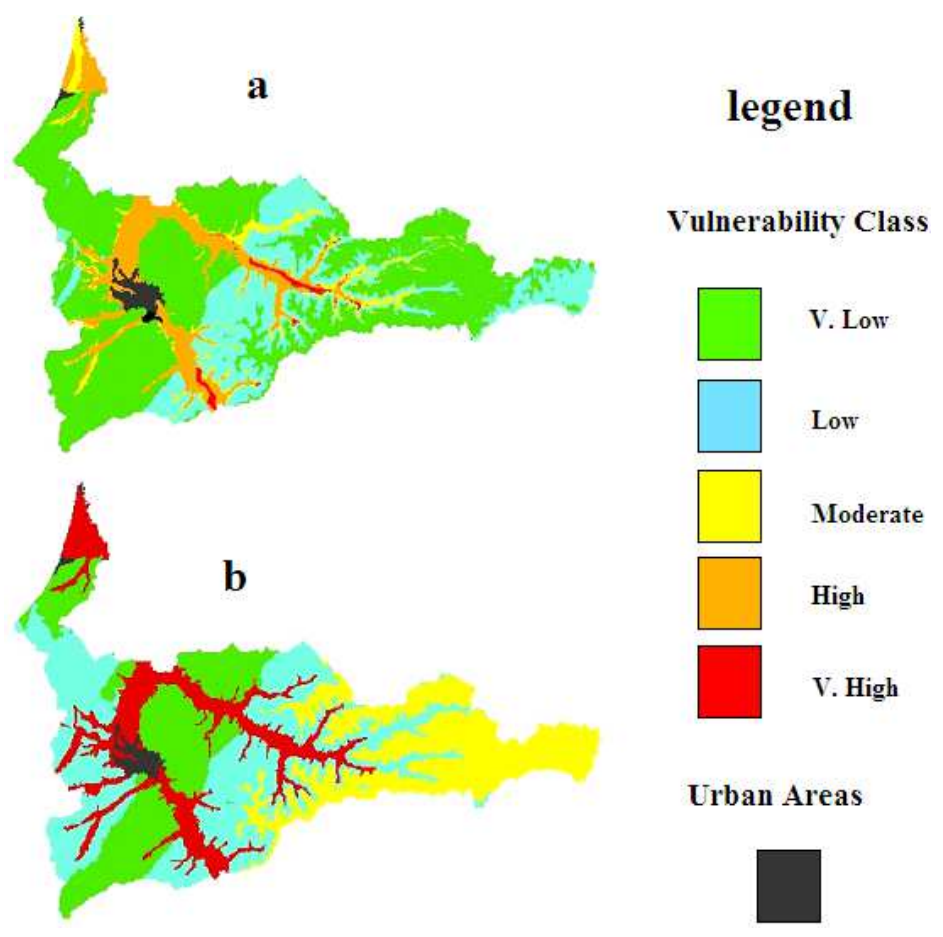

Fig. 4. Groundwater vulnerability to contamination in the study area: (a) using DRASTIC Model (b) Using GOD Model

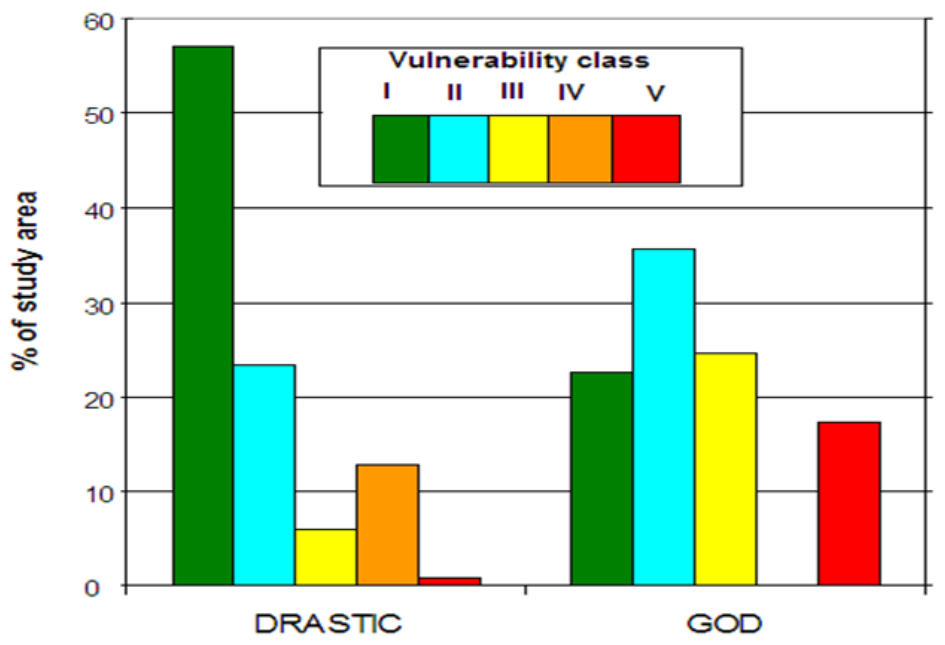

Fig. 5. Percent share of the vulnerability classes in the area of Portoviejo Canton using DRASTIC and GOD models 


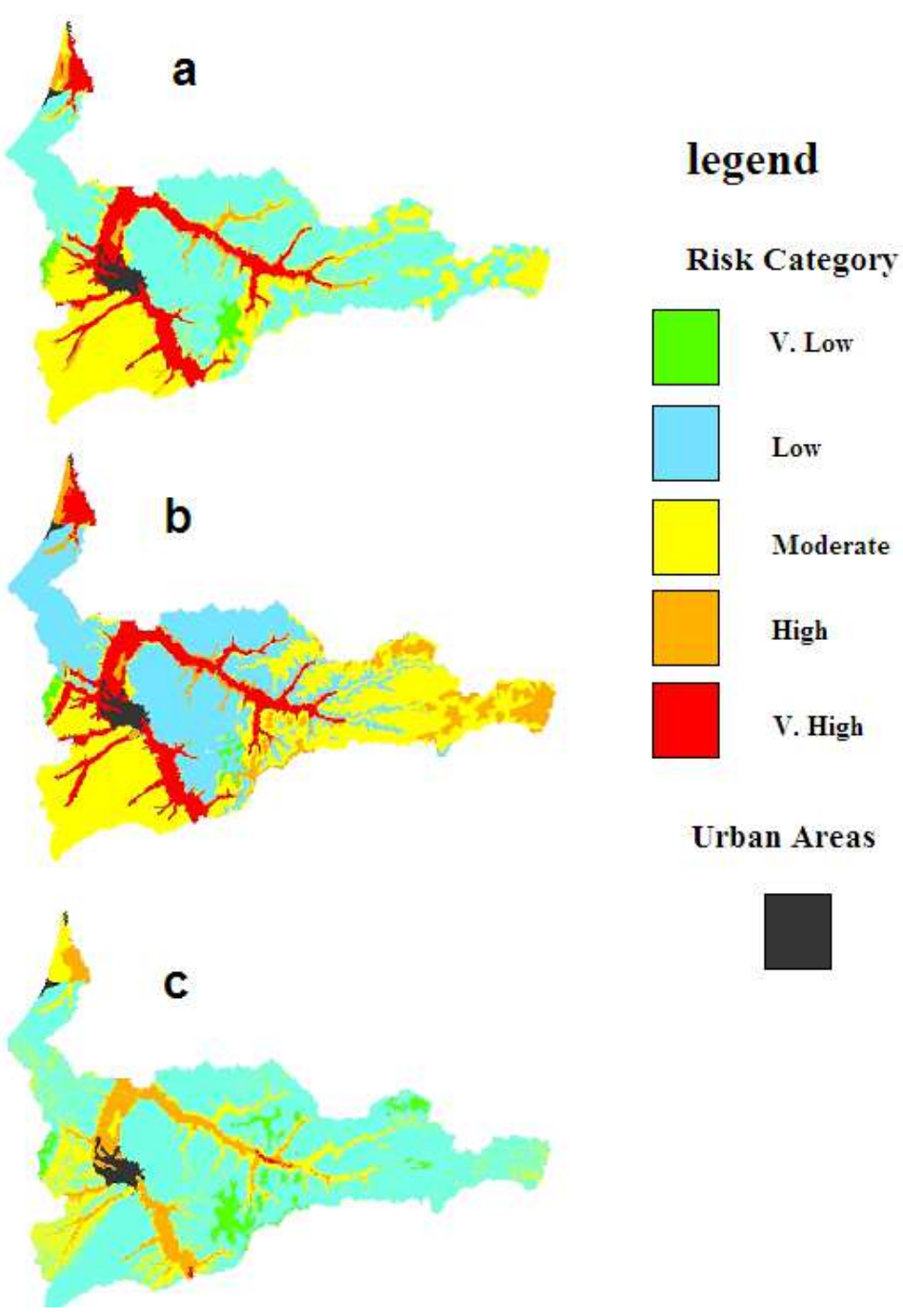

Fig. 6. The Risk of Groundwater contamination in the study area (a) Using DRASTIC Model (b) Using GOD Model (c) Using SI Model

Table 6. Spatial distribution comparison between DRASTIC and GOD vulnerability classes

\begin{tabular}{|c|c|c|c|c|c|c|}
\hline & & & & & & \\
\hline & & I & II & III & IV & $\mathrm{V}$ \\
\hline GOD & I & 22.669 & & & & \\
\hline & II & 14.146 & 19.32 & 2.164 & & \\
\hline & III & $\underline{20.54}$ & 3.69 & 0.554 & & \\
\hline & IV & & & & & \\
\hline & $\mathrm{V}$ & & $\underline{0.468}$ & $\underline{3.313}$ & 12.8 & 0.82 \\
\hline
\end{tabular}

Bold: Total coincidence, Italic: One class of difference, Underlined: More than one class of difference

Table 7. Classification the study area to different risk categories using DRASTIC, GOD and SI model

\begin{tabular}{|c|c|c|c|c|c|}
\hline \multirow[b]{2}{*}{ Model } & \multicolumn{4}{|c|}{ Risk Category (\% of total Study area) } & \multirow[b]{2}{*}{$\mathrm{V}$} \\
\hline & I & II & III & IV & \\
\hline DRASTIC & 1.85 & 51.33 & 30.60 & 4.46 & 11.76 \\
\hline GOD & 1.00 & 36.31 & 39.89 & 9.14 & 13.66 \\
\hline SI & 3.70 & 68.22 & 18.87 & 9.03 & 0.18 \\
\hline
\end{tabular}


Table 8. Spatial distribution comparison between DRASTIC, GOD and SI model risk categories. Values expressed as percentage of total study area

\begin{tabular}{|c|c|c|c|c|c|c|c|c|c|c|c|c|}
\hline & & & \multicolumn{5}{|c|}{ DRASTIC } & \multicolumn{5}{|c|}{ SI } \\
\hline & & & I & II & III & IV & $\mathrm{V}$ & I & II & III & IV & $\mathrm{V}$ \\
\hline \multirow[t]{5}{*}{ GOD } & Risk Category & I & 1 & - & - & - & - & 0.88 & 0.12 & - & - & - \\
\hline & & II & 0.64 & 33.92 & 1.5 & - & 0.25 & 0.64 & 32.89 & 2.76 & 0.02 & - \\
\hline & & III & 0.21 & 17.39 & 21.67 & 0.62 & $\overline{-}$ & $\underline{0.71}$ & 31.28 & 7.9 & $\overline{-}$ & - \\
\hline & & IV & - & 0.02 & 7.02 & 1.97 & 0.13 & $\overline{1.47}$ & 3.93 & 3.67 & 0.07 & - \\
\hline & & $\mathrm{V}$ & - & - & $\underline{0.41}$ & 1.87 & 11.38 & $\overline{-}$ & $\overline{-}$ & 4.54 & 8.94 & 0.18 \\
\hline \multirow[t]{5}{*}{ SI } & Risk Category & I & 1.53 & 0.7 & $\overline{1.47}$ & - & - & & & & & \\
\hline & & II & 0.13 & 48.97 & $\overline{19.03}$ & $\underline{0.06}$ & $\underline{0.03}$ & & & & & \\
\hline & & III & 0.19 & 1.66 & 10.09 & $\overline{4.02}$ & $\overline{2.91}$ & & & & & \\
\hline & & IV & $\overline{-}$ & - & 0.01 & 0.38 & $\overline{8.64}$ & & & & & \\
\hline & & $\mathrm{V}$ & - & - & - & - & 0.18 & & & & & \\
\hline
\end{tabular}

Bold: Total coincidence, Italic: One class of difference, Underlined: More than one class of difference

The results of DRASTIC risk show that $11.76,4.46$, $30.6,51.33$ and $1.85 \%$ of the study area belong to very high risk, high risk, moderate risk, low risk and very low risk respectively. Similarly, the results of GOD risk show that $13.66,9.14,39.89,36.31$ and $1 \%$ of the study area belong to very high risk, high risk, moderate risk, low risk and very low risk respectively. The results of SI model risk show that $0.18,9.03,18.87,68.22$ and $3.7 \%$ of the study area belong to very high risk, high risk, moderate risk, low risk and very low risk respectively (Table 7).

Table 8 shows the aerial and spatial distribution for risk categories derived from the 3 models. The spatial coincidence between DRASTIC and GOD vulnerability classes is $70 \%$. The spatial coincidence between DRASTIC and SI vulnerability classes is $61 \%$ and the spatial coincidence between GOD and SI vulnerability classes is $42 \%$. If we consider one vulnerability class as acceptable error the spatial coincidence rise to 99,95 and $89 \%$ between DRASTIC and GOD, DRASTIC and SI, GOD and SI respectively. The results demonstrate that DRASTIC is more close to both models which seem very reasonable. That's because it shares same contaminant load classification with GOD model and shares 4 parameters out of seven with SI model. The least coincidence is between GOD and SI. They shares just the $\mathrm{D}$ parameter, furthermore, it has different weight in each model.

Where, the contaminant load govern $50 \%$ of the risk value output in GOD and DRASTIC models.

Worldwide, DRASTIC model is more common than GOD and SI. The actual study shows a comparable result especially for evaluation the risk of groundwater contamination. That may indicate the ability of using GOD or SI as an alternatives to DRASTIC model. Furthermore, DRASTIC requires more data than the other two models, so in the conditions of data limitation, using GOD or SI models could represents a good advantage.

\section{Conclusion}

- The results shows that both, DRASTIC and GOD models were able to classify the study area to several zones of distinct vulnerability

- The spatial coincidence in the same vulnerability class using DRASTIC and GOD model is $43 \%$, but the coincidence become more than $76 \%$ if one vulnerability class shift is considered as acceptable error

- DRASTIC and GOD models agree that the areas close to Portoviejo River have higher vulnerability than areas more far from river course

- The results of groundwater risk of contamination maps show that DRASTIC, GOD and SI agree that the areas surrounding the River Portoviejo is of highest risk, although their findings may vary considerably in the areas with less groundwater contamination risk

- GOD risk results are the closest to DRASTIC results, because both use the same contaminated load values

- The results of SI model is more close to DRASTIC model than to GOD, because they share 4 parameters

- Accepting one risk category as acceptable error, the coincidence in the three models results is very high, where it is ranging between 89 to more than $97 \%$

- In the presence of detailed information about the hydrogeological system, DRASTIC is best because it incorporates more parameters. The SI and GOD models may be preferred to study the risk of groundwater contamination especially when detailed information is lacking

\section{Acknowledgment}

The author received funding from the Ecuador Republic Secretariat for Higher Education, Science, Technology and Innovation (SENESCYT) through PROMETEO Project. The author was hosted by Manabí Technical University (MTU) - Faculty of 
Agricultural Engineering (from 12/9/2014 to 7/6/2015). The author is grateful to the president of MTU, Eng. Vicente Véliz Briones and to the dean of Agricultural Engineering Faculty, Eng. Cesar Jarre for their support to overcome the technical challenges. Also, the author would like to thank the Department of international relations staff, for their role in facilitating the logistical supports needed for this research. Thanks also go to Eng. Adrian Reyna who provided the study with several data including some valuable base maps.

\section{Ethics}

The author declares that this is an original research and they have no ethical issues or copyrights conflict.

\section{References}

Abdelmajid, B. and S. Omar, 2009. Assessment of groundwater pollution by nitrates using intrinsic vulnerability methods: A case study of the Nil valley groundwater (Jijel, North-East Algeria). Afr. J. Environ. Sci. Technol.

Albinet, M. and J. Margat, 1970. Cartographie de la vulnrabilite a la pollution des nappes d'eau souterraine [Mapping of groundwater vulnerability to contamination]. Bull. BRGM, 2: 13-22.

Albuquerque, M.T.D., G. Sanz, S.F. Oliveira, R. Martínez-Alegría and I.M.H.R. Antunes, 2013. Spatio-temporal groundwater vulnerability assessment-a coupled remote sensing and GIS approach for historical land cover reconstruction. Water Resource Manage., 27: 4509-4509.

DOI: $10.1007 / \mathrm{s} 11269-013-0422-0$

Aller, L., T. Bennet, J.H. Lehr and R.J. Petty, 1987. DRASTIC: A standardized system for evaluating groundwater pollution potential using hydrogeologic settings. U.S. EPA Report 600/2-87-035. Ada, Oklahoma.

Al-Rawabdeh, A.M., N.A. Al-Ansari, A.A. Al-Taani, F. Al-Khateeb and S. Knutsson, 2014. Modeling the risk of groundwater contamination using modified DRASTIC and GIS in Amman-Zerqa Basin, Jordan. Open Eng., 4: 264-280. DOI: $10.2478 / \mathrm{s} 13531-013-0163-0$

Babiker, I.S., M.A.A. Mohamed, T. Hiyama and K. Kato, 2005. A GIS-based DRASTIC model for assessing aquifer vulnerability in Kakamigahara Heights, Gifu Prefecture, central Japan. Sci. Total Environ., 345: 127-140.

DOI: $10.1016 /$ j.scitotenv.2004.11.005

Barboza, A.E.C., S.F. Rocha and W.D. GuimarlEs, 2007. Estudo preliminar da vulnerabilidade do aquيfero livre localizado na regi Velha-ES, Florianpolis. In: SIMPwSIO BRASILEIRO DE SENSORIAMENTO REMOTO, 13. Anais... INPE, pp: 3279-3286.
Beynen, P.E., M.A. Niedzielski, B. Jelinska, K. Alsharif and J. Matusick, 2012. Comparative study of specific groundwater vulnerability of a karst aquifer in central Florida. Applied Geogr., 32: 868-877. DOI: 10.1016/j.apgeog.2011.09.005

Brindha, K. and L. Elango, 2015. Cross comparison of five popular groundwater pollution vulnerability index approaches. J. Hydrol., 524: 597-613. DOI: $10.1016 /$ j.jhydrol.2015.03.003

Connell, L.D. and G. Van den Daele, 2003. A quantitative approach to aquifer vulnerability mapping. J. Hydrol., 276: 71-88. DOI: $10.1016 / \mathrm{S} 0022-1694(03) 00038-6$

Díaz, E.L., E.C. Romero, N.G. Boschetti and O.C. Duarte, 2009. Groundwater vulnerability in the Arroyo Feliciano basin. Entre Rios. Argentina. Boletيn Geolgico y Minero, 120: 533-542.

Ecuadorian National Assembly. http://www.asambleanacional.gob.ec/es/contenido/le y-de-aguas-una-historia-de-lucha-hacia-el-buenvivir

Foster, S., 1987. Fundamental concept in aquifer vulnerability pollution risk and protection strategy. Proceedings of the International Conference Vulnerability of Soil and Groundwater to Pollution Nordwijk, (GPN' 87), The NetherLands.

Foster, S. and R. Hirata, 1988. Groundwater pollution Risk Assessment: A methodology based on available data. CEPIS/PAHO Technical Report, Lima, Peru.

Gaieb, S. and M.H. Hamza, 2013. Assessing vulnerability to agricultural pollution of groundwater Bou Arada Laroussa according to SI method applied by GIS. J. Res. Environ. Earth Sci.

Garcia, L., C. Moreira and O. Murillo, 2010. Contaminacin fيsico-quيmica en el rọo Portoviejo de la provincia de Manabs, entre los puentes Velasco Ibarra y puente El Salto, durante el periodo 2009-2010. Tesis De Grado no Publicado.

Ghazavi, R. and Z. Ebrahimi, 2015. Assessing groundwater vulnerability to contamination in an arid environment using DRASTIC and GOD models. Int. J. Environ. Sci. Technol., 12: 2909-2909. DOI: 10.1007/s13762-015-0813-2

Golder and Monahan, 2005. Golder and Monahan: Golder Associates Ltd. and Monahan Petroleum Consulting. Report on: Groundwater vulnerability mapping - Township of Langley, Langley, British Columbia.

Gogu, R., V. Hallet and A. Dassargues, 2003. Comparison between aquifer vulnerability assessment techniques. Environ. Geol., 44: 881-892.

Gougazeh, M. and S. Sharadqah, 2009. Groundwater vulnerability to contamination in Jordan evaluated in two levels of analysis. Jordan J. Civil Eng., 3: 314-321. 
Hamerlinck, J.D. and C.S. Ameson, 1998. Wyoming groundwater vulnerability assessment handbook. University of Wyoming, Laramie, Wyoming, Spatial Data Visualization Center, Report SDVC 98-01.

INAMHI, 2014. National Institute of Meteorology and Hydrology. Rainfall data.

INAMHI, 2016. Average multiannual precipitation map. Instituto Nacional de Meteorolog ب e Hidrologa.

Jaunat, J., F. Huneau, E. Garel, A. Devos and O. Lejeune, 2016. Assessment of intrinsic vulnerability of an alluvial aquifer under anthropogenic pressure: cross comparison of 4 index-based groundwater vulnerability mapping models within the Biguglia lagoon watershed (Corsica, France). Geophys. Res. Abstracts.

Kumar, P., B.K.S. Bansod, S.K. Debnath, P.K. Thakur and C. Ghanshyam, 2015. Index-based groundwater vulnerability mapping models using hydrogeological settings: A critical evaluation. Environ. Impact Assess. Rev., 51: 38-49.

DOI: $10.1016 /$ j.eiar.2015.02.001

Lobo-Ferreira, J.P. and M.M. Oliveira, 2003. Groundwater vulnerability assessment in Portugal. Geofssica Int., 43: 541-550.

Lynch, S.D., A.G. Reynders and R.E. Schulze, 1997. A drastic approach to ground water vulnerability in South Africa. S African.

Macias, R. and S. Dي̣az, 2010. Estrategias generales para el control y prevencin de la contaminacin del agua superficial en la cuenca del Rي portoviejo. Revista CENIC. Ciencias Biolgicas, 41: 1-7.

MAGAP, 2015a. Ministry of Agriculture, Livestock, Aquaculture and Fishing. Hydrogeological map of Ecuador.

MAGAP, 2015b. Ministry of Agriculture, Livestock, Aquaculture and Fishing. Geological map of Ecuador.

MAGAP, 2002a. Ministry of Agriculture, Livestock, Aquaculture and Fishing. Soil Taxonomy.

MAGAP, 2002b. Ministry of Agriculture, Livestock, Aquaculture and Fishing. Soil Texture.

MAGAP, 2002c. Ministry of Agriculture, Livestock, Aquaculture and Fishing. Land use map.

Mendoza, J.A. and G. Barmen, 2006. Assessment of groundwater vulnerability in the Río Artiguas basin, Nicaragua. Environ. Geol., 50: 569-580. DOI: 10.1007/s00254-006-0233-1

Nolan, B.T., K.J. Hitt and B.C. Ruddy, 2002. Probability of nitrate contamination of recently recharged groundwaters in the conterminous United States. Environ. Sci. Technol., 36: 2138-2145. DOI: $10.1021 / \mathrm{es} 0113854$

NRC, 1993. Groundwater Vulnerability Assessment: Contamination Potential under Conditions of Uncertainties. 1st Edn., National Academy Press, Washington, D.C., pp: 185.
Olmar, M. and B. Rezac, 1974. Methodical principles of maps for protection of ground water in Bohemia and Moravia, scale 1/200000. Mem. IAH 10 (1). Cited in: Barroco, G. and G. Biallo (1993). Application of GIS for aquifer vulnerability evaluation. IAHS.

Reina, E.R. and C.E. Zambrano, 2010. Investigacion de la calidad de agua del rio Portoviejo y Rio Chico como fuentes de abastecimiento para la planta de tratamiento de agua potable para la ciudad de Manta. Tesis de Grado. Universidad Laica "Eloy Alfaro" de Manabi.

Ribeiro, L., 2000. Desenvolvimento de um indice para avaliar a susceptibilidade dos aquiferos à contaminaç^o, Nota interna, (n户o publicada), ERSHA-CVRM.

Ribeiro, L., E. Serra, E. Paralta and J. Nascimento, 2003. Nitrate pollution in hard rock formations: Vulnerability and risk evaluation by geomathematical methods in Serpa-Brinches aquifer (south Portugal). Proceedings of the IAH International Conference on Groundwater in Fractured Rocks, (GFR' 03), Prague, Czech Republic, pp: 377-378.

Rosen, L., 1994. A study of the DRASTIC methodology with emphasis on Swedish conditions. Groundwater, 32: 278-285.

DOI: $10.1111 / \mathrm{j} .1745-6584.1994 . t b 00642 . x$

Rupert, M.G., 2001. Calibration of the DRASTIC ground water vulnerability mapping method. Groundwater, 39: 625-630. DOI: $10.1111 / \mathrm{j} .1745-6584.2001 . t b 02350 . \mathrm{x}$

Sasal, M.C., M.G. Wilson, M. Santi, J.D. Oszust and G.A. Schuls et al., 2011. Aplicacin del modelo DRASTIC en la cuenca del arroyo Las Conchas, Entre Ropos RIA. Revista de Investigaciones Agropecuarias, 37: 150-158.

Sharadqah, S., 2001. Evaluacín del riesgo de contaminacin de las aguas subterruneas en Jordania. Trabajo de Investigacin. Universidad Politécnica de Valencia.

Sharadqah, S., 2004. Evaluacin de la vulnerabilidad y el riesgo de contaminacín de las aguas subterr Jneas por nitrato en la huerta de Valencia mediante el acople de los modelos DRASTIC y GLEAMS a un sistema de informacin geogrJfica. PhD Thesis, Politechnical University of Valencia

Sharadqah, S., 2010. Assessing the Risk of Groundwater Nitrate Contamination in north Jordan by using DRASTIC model implemented in a Geographic Information System. Proceedings of the International Conference Geotunes, (ICG' 10), Tunes.

Sharadqah, S., 2011. Assessing the risk of groundwater contamination in western Irbid. Proceedings of the 10th International Conference of Jordanian Geologists Association and the 7th International Symposium on Middle East Geology, (MEG' 11), Amman. 
Sharadqah, S., 2015a. Groundwater Vulnerability to Contamination in the Canton of Portoviejo using DRASTIC methodology. Proceedings of the Geomatics of Middle East and North Africa Conference, Mar. 31-Apr. 3, Aqaba, Jordan.

Sharadqah, S., 2015b. Evaluation of groundwater risk of contamination in the canton of PortoviejoEcuador, using intrinsic vulnerability models. Proceedings of the 8th International Conference for Water Resources and Environment, Oct. 1922, Istanbul, Turkey.

Stigter, T.Y., L. Ribeiro and A.M.M. Carvalho Dill, 2006. Evaluation of an intrinsic and a specific vulnerability assessment method in comparison with groundwater salinisation and nitrate contamination levels in two agricultural regions in the south of Portugal. J. Hydrogeol., 14: 79-99. DOI: $10.1007 / \mathrm{s} 10040-004-0396-3$

Stumm, W. and J.J. Morgan, 1996. Aquatic Chemistry, Chemical Equilibrium and Rates in Natural Waters. 3rd Edn., John Wiley and Sons, Inc., New York, pp: 1022.

Tavares, P.R.L., M.A.H. Castro, C.T.F. Costa, J.G.P. Silveira and F.J.B. Almeida Jenior, 2009. Mapeamento da vulnerabilidade à contaminaçৎo das Jguas subterrâneas localizadas na bacia Sedimentar do Araripe, Estado do CearJ, Brasil. REM - Revista Escola de Minas, 62: 227-236.
Vogel, M.M., 2008. Avaliaç^o da vulnerabilidade natural à contaminaç^o dos recursos hdricos subterrâneos na regi $>$ o cultural da quarta colônia de imigraç^o italiana. Rio Grande do Sul: Universidade Federal de Santa Maria, Centro de Ciências Naturais e Exatas, Programa de Pś-graduaçəo em Geografia e Geociências, Brasil.

Voudouris, K., N. Kazakis, M. Polemio and K. Kareklas, 2010. Assessment of intrinsic vulnerability using DRASTIC model and GIS in Kiti aquifer Cyprus. European Water.

Vrba, J. and A. Zaporozec, 1994. Guidebook on Mapping Groundwater Vulnerability. 1st Edn., Heise, Hannover, ISBN-10: 3922705979, pp: 131.

$\mathrm{Xu}$, J., L.G. Xu and L. Dong, 2013. Evaluation model of ground water vulnerability and its application. Adv. Mater. Res. Vols., 610-613: 811-816.

DOI: 10.4028/www.scientific.net/AMR.610-613.811 